\title{
*: THRESHOLD IRRADIATION DOSE FOR AMORPHIZ̈ATION OF SILICON CARBIDE
}

\author{
L. L. SNEAD AND S. J. ZINKLE
}

Oak Ridge National Laboratory, Oak Ridge, TN 37831-6087.

\section{ABSTRACT}

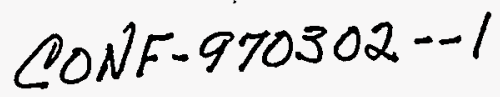

The amorphization of silicon carbide due to ion and electron irradiation is reviewed with emphasis on the temperature-dependent critical dose for amorphization. The effect of ion mass and energy on the threshold dose for amorphization is summarized, showing only a weak dependence near room temperature. Results are presented for $0.56 \mathrm{MeV}$ silicon ions implanted into single crystal $6 \mathrm{H}-\mathrm{SiC}$ as a function of temperature and ion dose. From this, the critical dose for amorphization is found as a function of temperature at depths well separated from the implanted ion region. Results are compared with published data generated using electrons and xenon ions as the irradiating species. High resolution TEM analysis is presented for the $\mathrm{Si}$ ion series showing the evolution of elongated amorphous islands oriented such that their major axis is parallel to the free surface. This suggests that surface or strain effects may be influencing the apparent amorphization threshold. Finally, a model for the temperature threshold for amorphization is described using the $\mathrm{Si}$ ion irradiation flux and the fitted interstitial migration energy which was found to be $\sim 0.56 \mathrm{eV}$. This model successfully explains the difference in the temperature dependent amorphization behavior of $\mathrm{SiC}$ irradiated with $0.56 \mathrm{MeV} \mathrm{Si}^{+}$at $1 \times 10^{-3} \mathrm{dpa} / \mathrm{s}$ and with fission neutrons irradiated at $1 \times 10^{-6} \mathrm{dpa} / \mathrm{s}$ irradiated to $15 \mathrm{dpa}$ in the temperature range of $\sim 340 \pm 10 \mathrm{~K}$.

\section{INTRODUCTION}

\section{NISTRIBUTIOH OF THS DOCUMENT IS UNLIMITED}

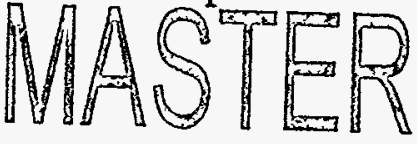

An understanding of the michostructural evolution of $\mathrm{SiC}$ under irradiation is critical to the application of these materials in fusion systems. At the expected application temperatures for $\mathrm{SiC}$ $\left(<1200^{\circ} \mathrm{C}\right)$ the most significant microstructural changes occur in the lower temperature regime. Specifically, at temperatures under $100^{\circ} \mathrm{C}$, volumetric swelling due to point defect induced strain has been seen to reach 3\%.1,2 At these low temperatures, amorphization of the $\mathrm{SiC}$ is also possible, which would lead to a substantial volumetric expansion of $\sim 15 \%,{ }^{3-5}$ along with correspondingly large changes in mechanical properties such as hardness and modulus. ${ }^{3}, 4,6$ Specifically, Snead et al. ${ }^{6}$ found that the elastic modulus for chemically vapor infiltrated $\mathrm{SiC}$ decreased from $400 \mathrm{GPa}$ in the unimplanted region, to $\sim 275 \mathrm{GPa}$ in the amorphized region. Likewise, the hardness was seen to decrease from $41 \mathrm{GPa}$ to $32 \mathrm{GPa}$. Similar behavior has been recently reported by other authors ${ }^{5}$ for ion irradiated $\mathrm{SiC}$.

Numerous studies ${ }^{3,7-14}$ have shown that $\mathrm{SiC}$ becomes amorphous during ion-beam irradiation at temperatures between $77 \mathrm{~K}$ and room temperature for damage levels of approximately 0.1 to 0.5 atomic displacements per atom (dpa.) To date there has been no demonstration of neutron induced amorphization of $\mathrm{SiC}$, although it is worth noting that there is a lack of low temperature high dose neutron irradiation data. The majority of studies relating to SiC amorphization have utilized low-energy $(<1 \mathrm{MeV})$ ion-beams ${ }^{8-14}$ with a few researchers studying the amorphization threshold using high energy electrons. ${ }^{15-19}$ These electron and ion irradiation studies have typically been carried out at temperatures between liquid nitrogen and $470 \mathrm{~K}$. Amorphization was not observed in $\mathrm{SiC}$ irradiated with fission neutrons (damage rate $\sim 10^{-7}$ $\mathrm{dpa} / \mathrm{s}$ ) at $\sim 420 \mathrm{~K}$ to damage levels in excess of $1 \mathrm{dpa}^{20}$

In the past ten years there has been a growing interest in the effect of irradiation temperature on the amorphization of silicon carbide. Specifically, Kinoshita ${ }^{15}$ and Matsunaga ${ }^{16}$ used $1 \mathrm{MeV}$ electron irradiation to measure the damage threshold for amorphization from liquid

"The submitted manuscript has been authored by a contractor of the U.S. Government under contract No.

DE-AC05-960R22464. Accordingly, the U.S. Government retains a nonexclusive, royalty-free license to publish or reproduce the published form of this contribution, or allow others to do so, for U.S. Government purposes." 


\section{DISCLAIMER}

Portions of this document may be illegible in electronic image products. Images are produced from the best available original document. 


\section{DISCLAIMER}

This report was prepared as an account of work sponsored by an agency of the United States Government. Neither the United States Government nor any agency thereof, nor any of their employees, make any warranty, express or implied, or assumes any legal liability or responsibility for the accuracy, completeness, or usefulness of any information, apparatus, product, or process disclosed, or represents that its use would not infringe privately owned rights. Reference herein to any specific commercial product, process, or service by trade name, trademark, manufacturer, or otherwise does not necessarily constitute or imply its endorsement, recommendation, or favoring by the United States Government or any agency thereof. The views and opinions of authors expressed herein do not necessarily state or reflect those of the United States Government or any agency thereof. 
nitrogen temperature to room temperature. Inui ${ }^{17-19}$ has used $2 \mathrm{MeV}$ TEM electrons and Weber ${ }^{5}$ ${ }^{21-24}$ has used a $1.5 \mathrm{MeV} \mathrm{Xe}$ beam in conjunction with (non damaging) TEM to study amorphization. In all cases the critical threshold for amorphization was measured as a function of temperature. It was observed that there is a temperature-independent amorphization dose at low temperatures followed by a temperature above which the damage level required to amorphize $\mathrm{SiC}$ increases rapidly. In each case an apparent asymptotic increase in the critical dose for amorphization occurred, yielding a critical temperature above which amorphization is apparently not possible. This value is reported to be significantly lower for electron irradiations compared to ion irradiations at the same damage rate of $\sim 1 \times 10^{-3} \mathrm{dpa} / \mathrm{s}$. The critical temperatures above which amorphization does not occur has been reported to range between $290 \mathrm{~K}$ and $340 \mathrm{~K}$ for electrons, ${ }^{17-19} \sim 420 \mathrm{~K}$ for Si ions ${ }^{25}$ and $\sim 490 \mathrm{~K}$ for Xe ions. ${ }^{23}$ It is noted that both Weber's ${ }^{21}$, 23 and Matsunaga's ${ }^{16}$ work did not observe a significant difference in amorphization threshold between $\alpha$ and $\beta \mathrm{SiC}$, whereas Inui reported $\sim 50 \mathrm{~K}$ lower threshold temperature for $\alpha$-SiC. ${ }^{17}$

\section{EXPERIMENTAL}

The materials chosen for this study were Cree Systems single crystal 6-H alpha SiC, Cercom hot pressed $\beta-\mathrm{SiC}$, and Carborundum sintered $\alpha-\mathrm{SiC}$ (Hexaloy). Four ion beams were selected for implantation in orientations both normal and parallel to the basal plane. Specifically, 3.6 MeV Fe and $0.56 \mathrm{MeV}$ Si ions were implanted as single beams, with a dual beam of $1.8 \mathrm{MeV}$ $\mathrm{Cl}$ and $1.0 \mathrm{MeV}$ He. The silicon beam was produced in the NV-500 accelerator at the SMAC user facility at $\mathrm{ORNL}$ while the $\mathrm{Fe}, \mathrm{Cl}$ and $\mathrm{He}$ ion beams were produced in the Triple Ion Beam Facility at ORNL. In both facilities, samples were heat sinked to a thermalizer block and temperatures measured using thermocouples either in contact with the thermalizer block or a backing to which the block was clamped. Typical ion beam fluxes were $7.1 \times 10^{11}$ to $2.6 \times 10^{12}$ ion $/ \mathrm{cm}^{2}$-s, producing peak displacement damage rates of $\sim 0.2$ to $1 \times 10^{-3} \mathrm{dpa} / \mathrm{s}$. Cross sectional transmission electron microscopy was performed on all samples. The determination of amorphization was made by bright and dark field imaging and the presence of spot-free, diffuse diffraction patterns. The amorphized band was measured and compared with the TRIM- $92^{26}$ code to determine the critical dose for amorphization. The damage calculations were obtained assuming a sublattice-averaged threshold displacement energy of $40 \mathrm{eV}$. High resolution TEM was performed with a JEOL 4000 microscope, while conventional microscopy was performed using a Philips CM-12 microscope. Samples prepared for microscopy were mechanically thinned and ion milled with argon ions at $6 \mathrm{keV}$ and $15^{\circ}$ using a liquid nitrogen cooled stage during milling. A final mill was performed at $3 \mathrm{keV}, 9^{\circ}$ for 10 minutes at ambient temperature to reduce surface amorphization associated with argon implantation.

Two TEM discs each of Carborundum sintered $\alpha$-SiC (Hexaloy) and hot pressed $\beta$-SiC produced by Cercom were irradiated in the target region of the High Flux İsotope Reactor in an aluminum capsule that was in direct contact with the reactor coolant water, producing a specimen irradiation temperature of $\sim 340 \mathrm{~K}$. The fast neutron $\left(\mathrm{E}>0.1 \mathrm{MeV}\right.$ ) fluence was $\sim 1.5 \times 10^{26 / \mathrm{m}^{2}}$ corresponding to a displacement level of $\sim 15 \mathrm{dpa}$ at a damage rate of $\sim 1 \times 10^{-6} \mathrm{dpa} / \mathrm{s}_{\mathrm{r}}$. Densities on these specimens were obtained using density gradient columns using mixtures of tetrabromethane-methylene iodide or ethylene bromide-bromoform for the unirradiated and irradiated samples, respectively. The accuracy of the measurement was better than $0.001 \mathrm{~g} / \mathrm{cc}$ and was found to be reproducible in repeated measurements and consistent for duplicate irradiated samples. 


\section{RESULTS AND DISCUSSION}

Amorphization of the single crystal $\mathrm{SiC}$ due to $3.6 \mathrm{MeV}$ Fe ion irradiation at room temperature is shown in Figure 1. The upper cross-sectional micrograph shows the highest fluence specimen $\left(5.7 \times 10^{15}\right.$ ions $\left./ \mathrm{cm}^{2}\right)$, which amorphized over the entire range. The electron diffraction pattern for the amorphous region is inset into Fig. 1a. At a fluence of $2.0 \times 10^{15}$ ions $/ \mathrm{cm}^{2}$ (Fig. 1b), amorphization only occurred over a $\sim 0.7 \mu \mathrm{m}$ wide band centered near the peak damage region. Amorphization was not observed at any depth at the lowest Fe ion fluence shown in Fig. 1c (1.4 $\times 10^{14}$ ions $/ \mathrm{cm}^{2}$ ), which produced $0.05 \mathrm{dpa}$ in the peak damage region. Similar results were obtained for CVD SiC irradiated with $\mathrm{Fe}$ ions at the same three fluences. ${ }^{25}$ No. significant difference was found in the amorphization behavior of the Cree single crystal 6H-SiC, CVD SiC or Cercom hot pressed $\beta$-SiC. Figure 1 also demonstrates the swelling associated with the amorphization of SiC. By comparison of Fig. 1a (totally amorphous) with the non-amorphized

a)
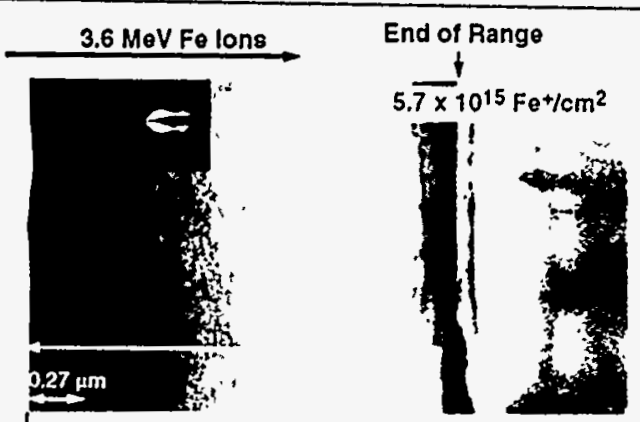

b)

c)

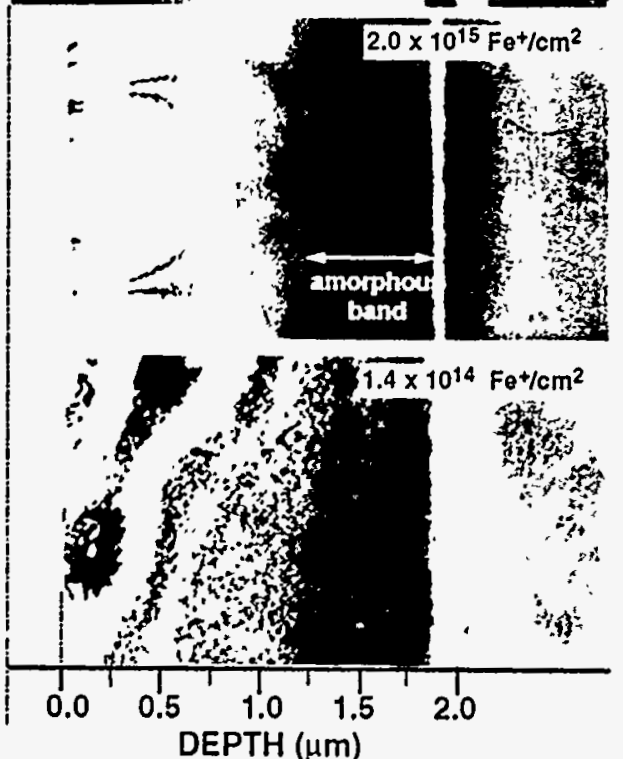

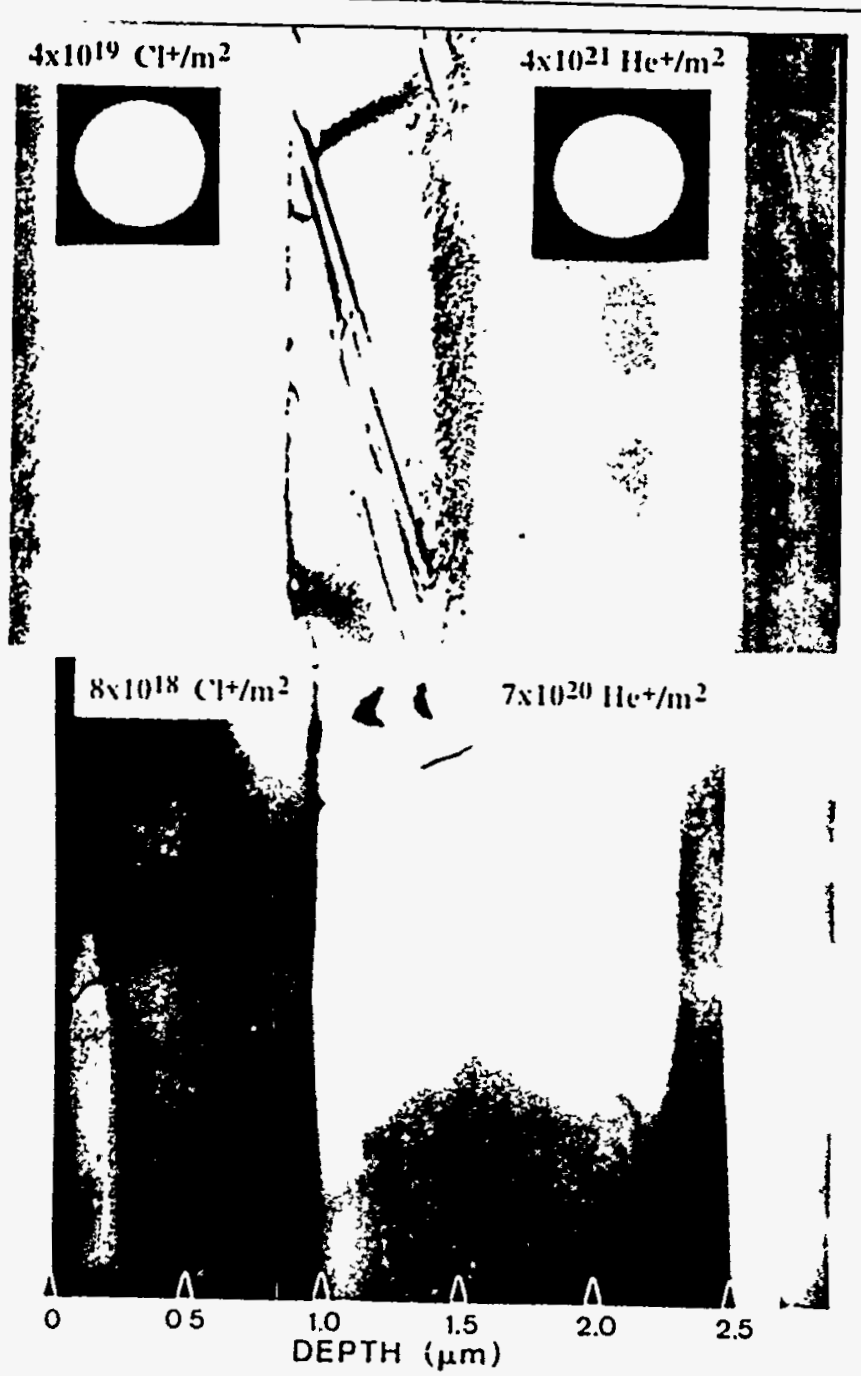

Figure $2: 1.8 \mathrm{MeV} \mathrm{Cl}$ and $1 \mathrm{MeV}$ He Ion Amorphized $\beta$-SiC
Figure $1: 3.6 \mathrm{MeV}$ Fe Ion Amorphized SiC Single Crystal 6H-SiC$$
\text { Amorphized } \beta \text {-SiC }
$$ 
sample (Fig. 1c), it is seen that amorphization has caused a significant volumetric expansion, with a resultant $0.27 \mu \mathrm{m}$ movement of the free surface to the left. From this free surface "stepheight" movement a volumetric swelling of $\sim 15 \%$ was calculated due to the crystal-to-amorphous transformation. ${ }^{25}$ Part of the original surface is missing from Fig. $1 \mathrm{~b}$ so the volumetric expansion associated with the $0.7 \mu \mathrm{m}$ amorphous band is not evident. From a comparison of the visible damage depths for the three $\mathrm{Fe}$ ion irradiation fluences, the amoint of volumetric swelling associated with amorphization was calculated to be $\sim 17 \% .^{25}$

Figure 2 shows the effect of a room temperature simultaneous irradiation of $1.8 \mathrm{MeV} \mathrm{Cl}$ and $1.0 \mathrm{MeV}$ He ions into a $\beta$-SiC sample. ${ }^{25}$ The $\mathrm{Cl}$ beam had a damage range of nearly $1 \mu \mathrm{m}$, and the He beam produced damage up to $2 \mu \mathrm{m}$. The upper micrograph of the figure is for the higher dose condition, and it is seen that amorphization has occurred over all but the near-surface regions of the $\mathrm{Cl}$ plus $\mathrm{He}$ ion irradiated region $(\sim 1.0 \mu \mathrm{m})$ and over the last third of the He ions irradiated region (maximum range $\sim 2.4 \mu \mathrm{m}$ due to density decrease associated with amorphization.) The lower ion doses shown in the bottom of this figure exhibit amorphization only near the end of the $\mathrm{Cl}$ and $\mathrm{He}$ ion ranges. Figure 2 also shows the effect of volumetric expansion, visible through the free surface movement. A measured swelling associated with amorphization of $17( \pm 3 \%)$ was measured for these specimens. The measured volume change associated with amorphization in $\mathrm{SiC}$ of $17 \%$ for the $\mathrm{Fe}, \mathrm{Cl}$ and $\mathrm{He}$ ion irradiation is somewhat lower than the $22 \pm 3 \%$ reported by Weber, but in good agreement with the value of $15 \%$ reported by McHargue. ${ }^{4}$

A matrix of samples was irradiated from room temperature to $400^{\circ} \mathrm{C}$ at several different $\mathrm{Si}$ ion fluences. Figure 3 shows examples of two different specimens that were irradiated to a $\mathrm{Si}$ ion fluence of $1.0 \times 10^{15} \mathrm{ions} / \mathrm{cm}^{2}$ at room temperature and $200^{\circ} \mathrm{C}$. The room temperature specimen contained a band of material starting at about mid-range $(\sim 0.3 \mu \mathrm{m})$ that appeared to be amorphous under ordinary bright field imaging conditions. However, through high resolution imaging a small volume fraction $(<5 \%)$ of dispersed islands of crystalline material was observed at the beginning half of the "amorphous" band and was absent at the end of the ion range. These crystalline islands account for the weak diffraction spots seen in the diffuse rings of the upper diffraction pattern of Fig. 3 and indicate that the material was on the verge of total amorphization. The $200^{\circ} \mathrm{C}$ irradiated sample given in the lower part of Fig. 3 shows no evidence of amorphization

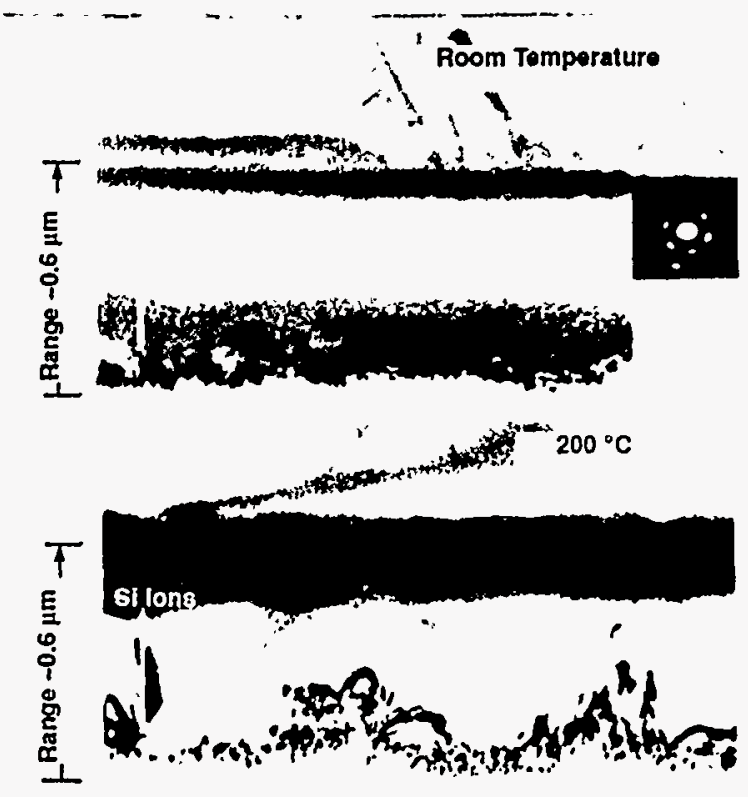

Figure 3 : Cross Sectional TEM of Si ion Implanted $\mathrm{SiC}$.

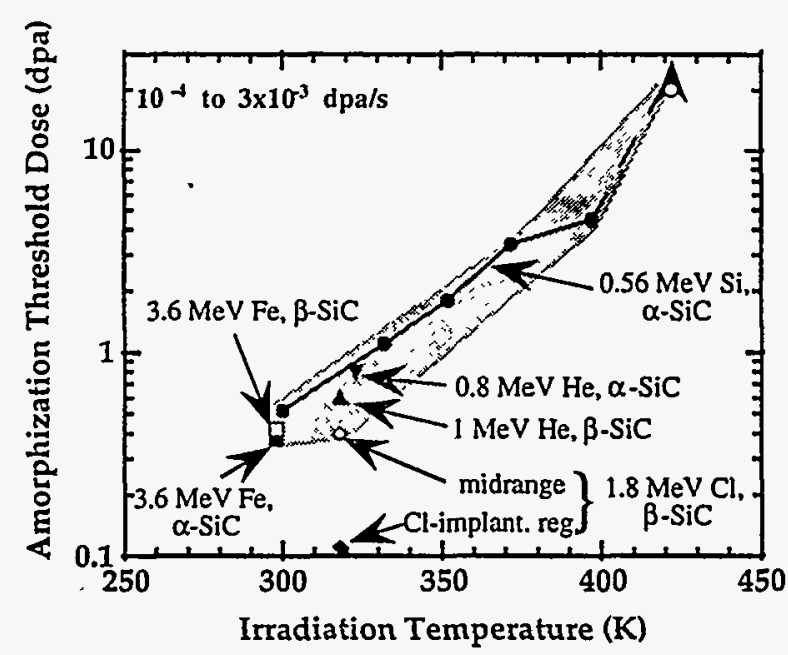

Figure 4 : Amorphization Threshold of $\mathrm{SiC}$ as a Function of Irradiation Temperature. 
for equal dose rates $\left(1 \times 10^{-3} \mathrm{dpa} / \mathrm{s}\right)$, indicating a temperature dependent dynamic recovery of the crystal.

The measured threshold for amorphization as a function of temperature for the Si ions and the other ions is given in Figure 4. As discussed previously, the presence of Fe and Si ions did not have any measurable effect on the threshold amorphization dose, whereas $\mathrm{Cl}$ ions significantly reduced the threshold dose for amorphization in the implanted ion region. 7,25 This enhancement of amorphization is clearly demonstrated in Fig. 4 for the $\mathrm{Cl}$ irradiated material near room temperature. The remaining data in Fig. 4 were all taken from the unimplanted regions. Figure 4 shows a rapid increase in the critical amorphization dose with increasing temperature. At $420 \mathrm{~K}$, no amorphization was observed in either the implanted or unimplanted regions at the highest $\mathrm{Si}$ ion dose studied, which was equivalent to $20 \mathrm{dpa}$.

These temperature dependent results are qualitatively consistent with previous studies which have used an in-situ technique for measuring the temperature dependent amorphization in $\mathrm{SiC}$. For the in-situ approach, an irradiating beam is passed through, or partially through, a thin section of material with real-time observation of the microstructural evolution using TEM. Specifically, Kinoshita ${ }^{15}$ and Matsunaga ${ }^{16}$ used $1 \mathrm{MeV}$ electrons while Inui ${ }^{17-19}$ has used $2 \mathrm{MeV}$ electrons to both damage and image the samples. Weber ${ }^{51-24}$ used a $1.5 \mathrm{MeV}$ Xe beam in conjunction with TEM. In these examples Inui found the amorphization dose threshold below room temperature to be approximately $1 \mathrm{dpa}$ for $\alpha-\mathrm{SiC}^{17}$ and about $0.5 \mathrm{dpa}$ for highly faulted $\beta$ $\mathrm{SiC}^{18}$ Weber $^{21}$ found the amorphization threshold near room temperature to be about $0.2 \mathrm{dpa}$ for $1.5 \mathrm{MeV}$ Xe ions. Figure 5 compares the data from the Si ion irradiations with the data from Inui and Weber, all of which were obtained at a damage rate near $1 \times 10^{-3} \mathrm{dpa} / \mathrm{s}$. All of the data in Fig. 5 have been plotted assuming an average displacement energy of $40 \mathrm{eV}$.

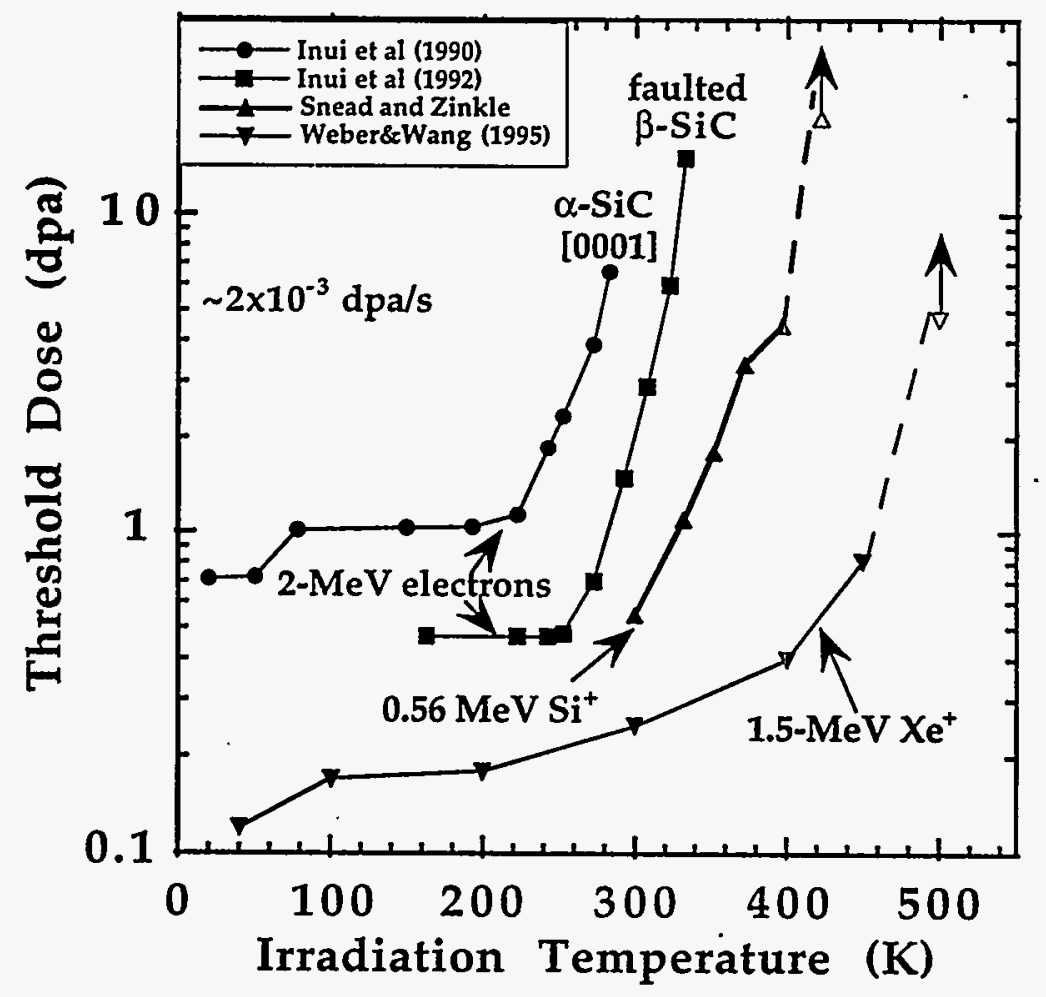

Figure 5 : Temperature Dependent Critical Dose for Amorphization of $\mathrm{SiC}^{25}$ 
The results of Fig. 5 raise interesting questions regarding the mechanism for amorphization in SiC. Because amorphization has occurred under electron irradiation it is apparent that the $\mathrm{SiC}$ crystal, in the cubic or hexagonal form, can be driven amorphous by simple defect accumulation alone. The Xe ions, which can transfer much higher energies to the lattice atoms than the electrons (or the $\mathrm{Si}$ ions), are apparently capable of amorphizing $\mathrm{SiC}$ to a much higher temperature than electrons at the same damage rate. While the Xe ions will cause relatively large cascades compared to $\mathrm{Si}$ ions, no cascades can form for the low energy transfer electron irradiations. This supports the possibility of amorphization beginning within cascade structures which would also explain why the Xe ions produce amorphization to a higher temperature than the $\mathrm{Si}$ ions. Alternatively, it is possible that the heavier Xe ions simply create a higher concentration of "stable" interstitials than the $\mathrm{Si}$ ions or electrons on a dpa-normalized basis, thus driving the temperature threshold higher.

A potential problem in comparing the amorphization threshold data sets presented in Fig. 5 is whether the in-situ approach of Inui and Weber ${ }^{5,17-19,21-24}$ can be directly compared with the ex-situ measurements of the present study. In other words, are there technique-dependent effects occurring for one or both types of amorphization measurements. One example of an experimental

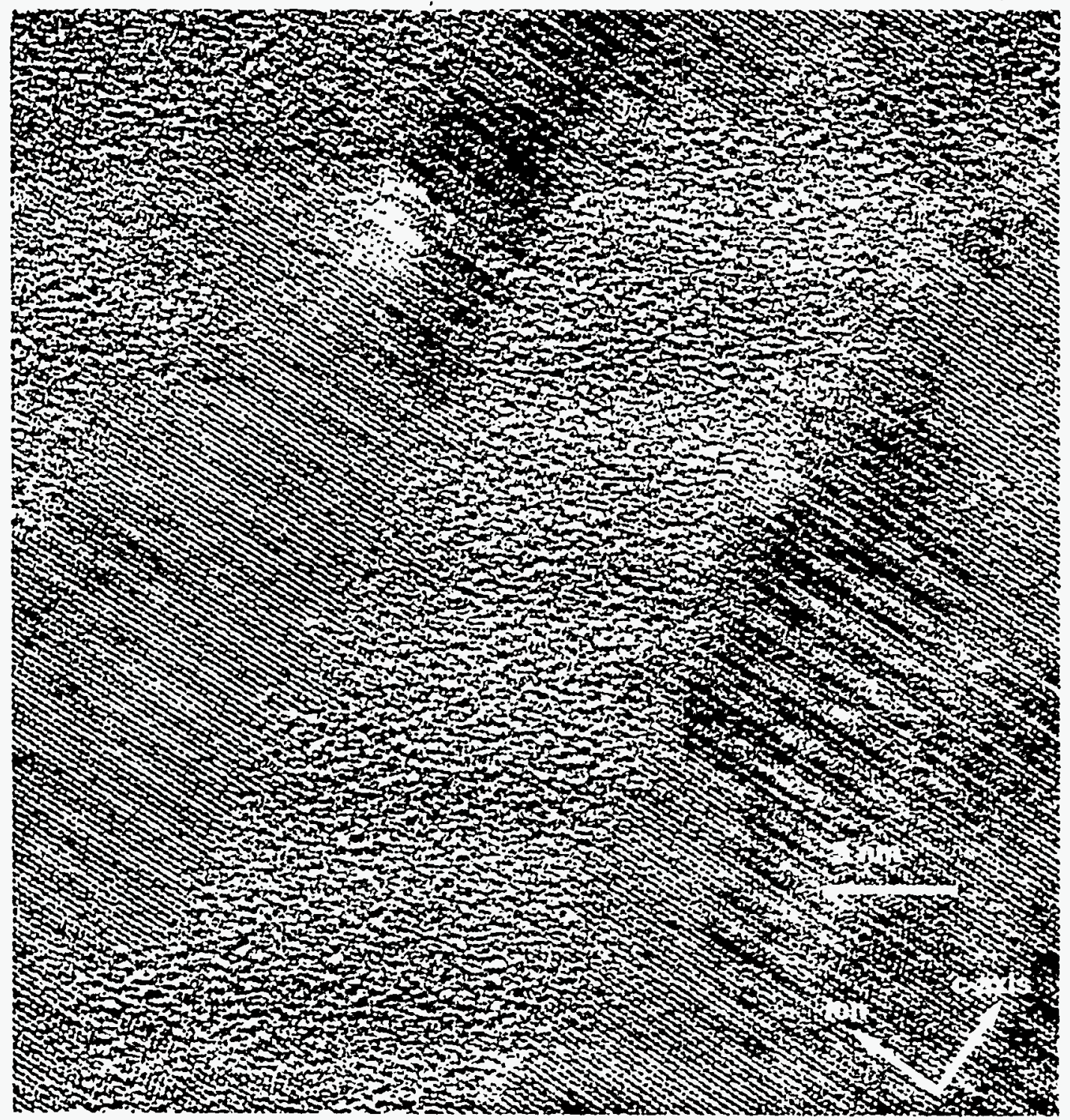

Figure 6 : HRTEM Image showing large island amorphous structures in $60^{\circ} \mathrm{C} \mathrm{Si}$ Irradiated SiC. 


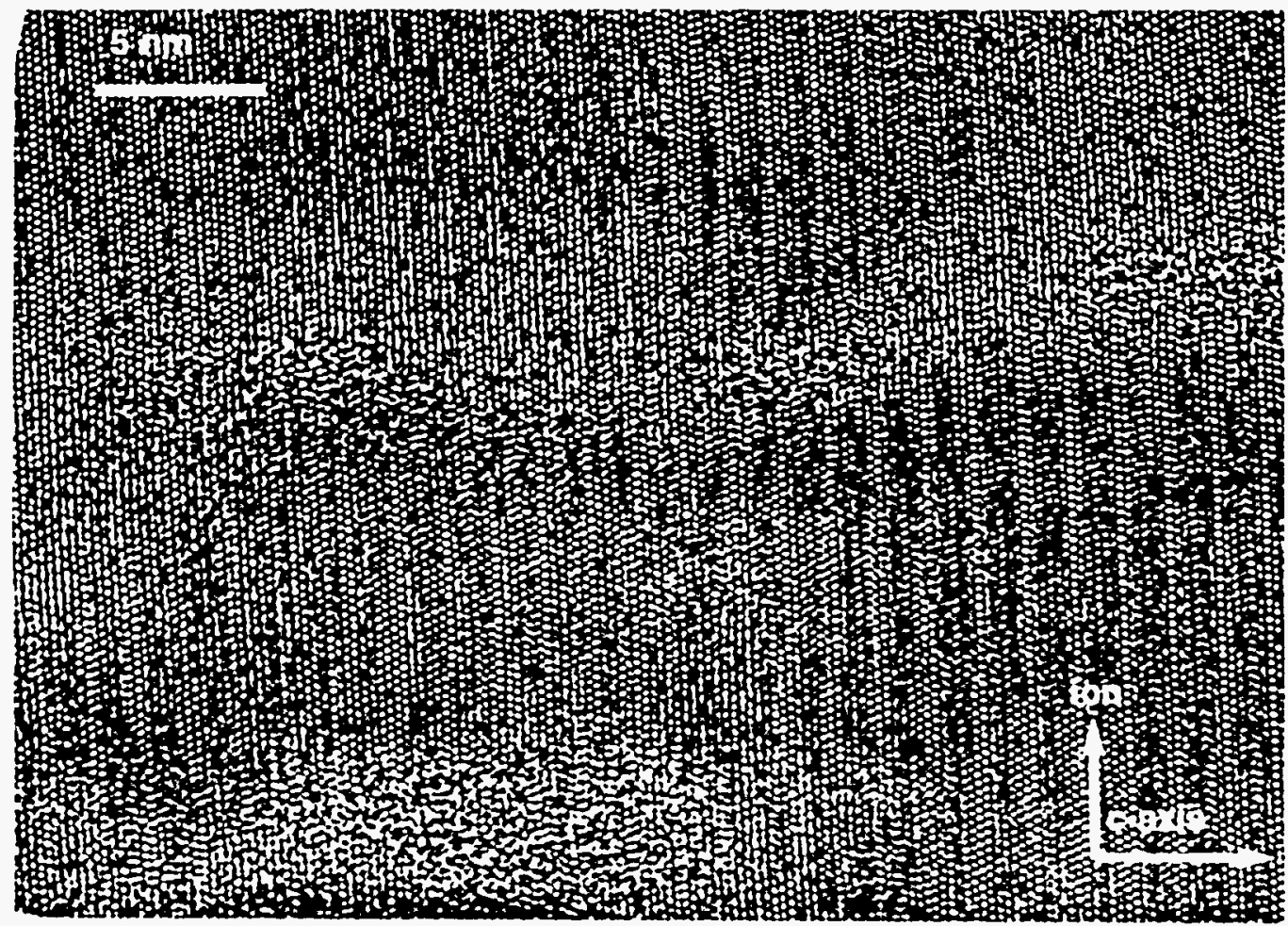

Figure $7:$ HRTEM image of Si irradiated SiC showing nucleation of island amorphous structures.

artifact is demonstrated by observing a series of high resolution TEM images from the $\mathrm{Si}$ implanted, single crystal $\beta$-SiC. In general, there is a fairly rapid transition from crystalline material into the amorphous band (see Figs. .1-3). As expected from the damage gradient of the ion profile, ${ }^{7}$ this transition region is wider at the near-surface side of the amorphization band compared to the end of the band (larger gradient in damage.) Figure 6 shows a HRTEM bright field image of the crystalline to amorphous transition region at the end of the amorphous band for a $6 \mathrm{H}-\mathrm{SiC}$ sample irradiated with $\mathrm{Si}$ ions normal to the c-axis at $60^{\circ} \mathrm{C}$. Fairly large areas of amorphous regions are seen, mixed into the crystal structure, which is consistent with the statistical nature of a point defect accumulation driven amorphization. Of particular interest in this micrograph is the shape and orientation of the amorphous areas, which appear to form as island structures with the major radii aligned parallel to the surface of the specimen. This phenomenon was observed in all amorphized specimens studied at both the beginning and end of the amorphized region from $60^{\circ} \mathrm{C}$ to $125^{\circ} \mathrm{C}$ for the Si ion irradiated specimens as well as the room temperature $6 \mathrm{H} \mathrm{SiC}$ and $\mathrm{CVD} \mathrm{SiC}$ specimens irradiated with $3.6 \mathrm{MeV} \mathrm{Fe}$. These anisotropic amorphous structures occur when the beam is injected normal to the c-axis (as in Fig. 6) or parallel to the $c$-axis and therefore is not a crystallographic orientation phenomenon. Figure 7 shows another bright field micrograph illustrating that the formation of these islands occurs on a very fine scale, eventually growing and linking with other islands.

In order to quantify this effect, a series of micrographs were taken at the beginning and end of the amorphized band for specimens irradiated with Si ions at 60 and $125^{\circ} \mathrm{C}$. Amorphous 
islands were identified using the complete loss of lattice fringes as the criteria, and the major and minor radius of each amorphous pocket was measured. Typically, about 50 islands were measured from at least three separate areas on each specimen. Results of this analysis showed that the aspect ratio (major/minor radius) was fairly constant independent of the temperature and location of the amorphous band. Specifically, the aspect ratio was found to be 3.3 and 3.1 for the beginning and end of the amorphous band for the $60^{\circ} \mathrm{C} \mathrm{Si}$ ion irradiated material and 3.2 and 3.6 at the beginning and end of the amorphous band for the $125^{\circ} \mathrm{C}$ irradiated material, respectively.

The anisotropic geometry of these islands relative to the surface of the specimens raises the question of whether there is a strain effect on the evolution of the amorphous structure. There is obviously a large lattice strain induced in the crystal to amorphous transition both from point defect accumulation and the amorphous pockets. Also, the presence of the free surface should affect the nature of the strain field. The obvious question from these results is whether the formation and connection of the amorphous pockets are being affected in a substantial way by this phenomenon. For example, it has been shown that the amorphization threshold is reduced in $\mathrm{Cl}$ ion implanted $\mathrm{SiC}^{7}$ Amorphous regions could nucleate first in such an implanted region causing a large stress field due to the associated volumetric expansion and contribute to drive the surrounding material amorphous. The presence of the free surface and/or the expansion of the material in a direction towards the surface could affect this strain field and the subsequent amorphization.

Chemical rate theory models have been developed by several authors which can be fitted to experimental amorphization data. However, these models contain numerous parameters which are not well known and generally do not have analytical solutions. More simplistic analytical models have been developed. ${ }^{21}$ However, these models have yielded unrealistically low activation energies for amorphization (below $0.1 \mathrm{eV}$ ), considering that the recovery processes occur near or above room temperature.

The data of Fig. 5 have been analyzed with an analytical approximation based on the rate theory model of Motta and Olander ${ }^{27}$ developed for electron induced amorphization of intermetallic precipitates in zircaloy. This model is analogous to well known rate theory results for point defect concentrations in irradiated metals and is based on the free energy increase associated with point defect accumulation, and is therefore not appropriate if in-cascade amorphization occurs. The assumption of point defect driven amorphization is supported by the molecular dynamics simulations ${ }^{28}$ and high-resolution TEM observations ${ }^{18,23}$ which indicate that amorphization in $\mathrm{SiC}$ proceeds gradually by point defect accumulation processes, as opposed to heterogeneous in-cascade amorphization. There is no evidence for the spontaneous creation of amorphous zones in displacement cascades in irradiated $\mathrm{SiC}^{23,28}$ though this should still be considered an open question.

Specifically, the model ${ }^{27}$ as applied to amorphization in $\mathrm{SiC}$ uses the temperature dependent term for the critical damage for amorphization (see,Fig. 5) which is given by :

$$
d(T)=\frac{A}{\sqrt{\phi}} e^{-\frac{E_{m}^{i}}{2 k T}}
$$

The critical dose for amorphization as given in Fig. 5 can be described by the sum of this temperature dependent term and the temperature independent term obtained at low temperatures:

$$
d p a_{c r i t}=d(T)+d_{0}
$$


The interstitial migration energy, $\mathrm{E}_{\mathrm{i}} \mathrm{m}$, is found from the slope of the experimental amorphization data; as plotted in Figure 8. The interstitial migration energy for the silicon ion irradiation was calculated to be $0.56 \mathrm{eV}$ and is in agreement with the data sets of Inui ${ }^{17}$ and Weber ${ }^{5}$ on $\alpha-\mathrm{SiC}$. The data by Inui ${ }^{19}$ on highly faulted $\beta-\mathrm{SiC}$ is significantly higher significantly higher than this value, however. All the data sets of this figure are at approximately the same displacement rate $\left(\sim 2 \times 10^{-3} \mathrm{dpa} / \mathrm{s}\right)$ rendering the pre-exponential term in equation (1) constant.

The physical explanation for the temperature-dependent behavior of the Motta and Olander amorphization model is associated with interstitial migration that assists restoration of chemical order in the lattice. We assume that amorphization occurs via chemical disordering on both the $\mathrm{Si}$ and $\mathrm{C}$ sublattices in $\mathrm{SiC}$. Experimental measurement of the threshold energy to induce amorphization in $\mathrm{SiC}$ during cryogenic temperature electron irradiation is needed to determine the validity of this assumption. The migration energy of $0.56 \mathrm{eV}$ is tentatively attributed to the slower interstitial specie (presumably Si). As shown in Fig. 5, both the $\alpha$-SiC electron irradiation ${ }^{17}$ and $\beta$-SiC Xe ion ${ }^{21}$ irradiation studies observed a step in the amorphization dose at low temperature $(\sim 70 \mathrm{~K})$ which may be due to migration of the faster interstitial specie, or perhaps recovery of close-pair Frenkel defects.

Referring again to Fig. 5, it is seen that for all the data sets used, amorphization has occurred in the temperature independent region at a displacement dose $\left(d_{0}\right)$ of less than $1 \mathrm{dpa}$. The temperature above which amorphization is not observed is $\sim 300 \mathrm{~K}$ for electron irradiated material, $\sim 420 \mathrm{~K}$ for $\mathrm{Si}$ ions, and $\sim 500 \mathrm{~K}$ for $\mathrm{Xe}$ ions. The $\mathrm{SiC}$ material which was neutron irradiated in this study to a dose of approximately 15 dpa yielded density changes of $10.1 \%$ for the

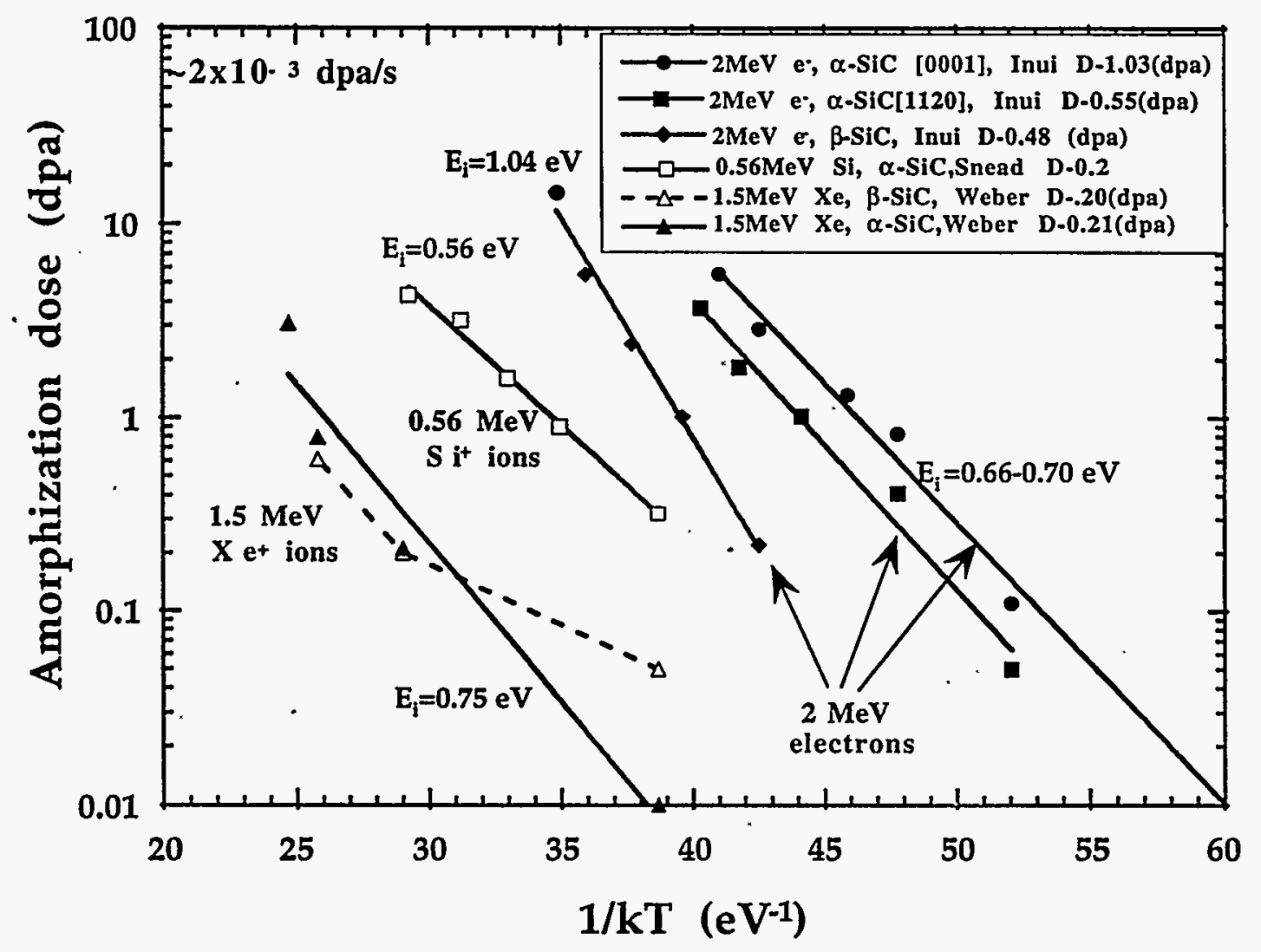

Figure 8 : Interstitial Migration Energy Determination for Amorphization of SiC. 
Cercom $\beta$-SiC and $11.1 \%$ for the Carborundum $\alpha-\mathrm{SiC}$. While both values are significantly higher than expected for simple "point defect "swelling from the previous neutron irradiation data for swelling in silicon carbide, it is less than the $15 \%$ swelling level reported for complete amorphization. However, given this large swelling which has occurred it is likely that the samples include pockets of amorphization. The neutron irradiation temperature for these samples was $\sim 350 \mathrm{~K}$.

Given that the fast neutron irradiation of $\mathrm{SiC}$ should produce a damage spectrum closer to the ion irradiated material than the simple point defect only spectrum of the electron irradiation it might be expected that complete amorphization should have occurred during neutron irradiation at the $350 \mathrm{~K}$ neutron irradiation. The apparent partial retention of the crystal structure for the neutron irradiated $\mathrm{SiC}$ specimens can be explained with the above rate theory model by noting that the damage rate for the neutron irradiation was $\sim 1 \times 10^{-6} \mathrm{dpa} / \mathrm{s}$ which is three orders of magnitude lower than the $\mathrm{Si}$ ion irradiation. Using the $0.56 \mathrm{eV}$ migration energy calculated from the $\mathrm{Si}$ ion data and using the respective damage rates, equation (2) can be used to plot the calculated threshold dose profile for amorphization at two different damage rates, as shown in Figure 9. This plot includes the silicon ion irradiation data along with its calculated profile and the data point for which amorphization was not observed ( $20 \mathrm{dpa}$ and $420 \mathrm{~K}$.)

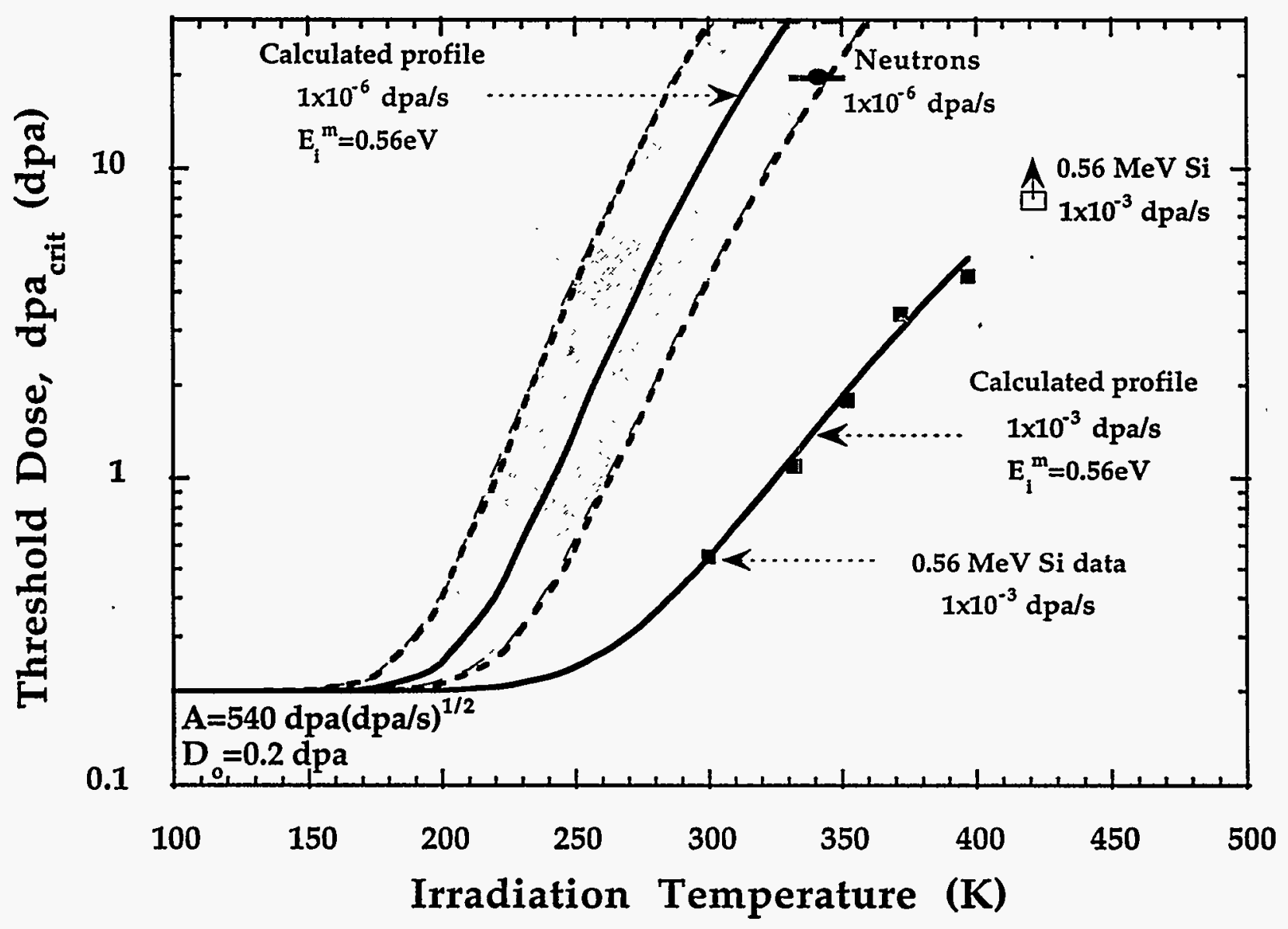

Figure 9: Predicted Flux Dependence of the Critical Dose for Amorphization of SiC 
The threshold dose profile for the fission neutron damage rate of $\sim 1 \times 10^{-6} \mathrm{dpa} / \mathrm{s}$ is calculated with the derived $0.56 \mathrm{eV}$ interstitial migration energy, and migration energies $\pm 0.05 \mathrm{eV}$ from this value, to demonstrate sensitivity to this variable. Given the nature of the calculation of the interstitial migration energy, such an uncertainty is conceivable. However, assuming a migration energy of $0.56 \mathrm{eV}$, it is seen that for the $\sim 340 \mathrm{~K}$ fission neutron irradiation temperature and $\sim 1 \times 10^{-6} \mathrm{dpa} / \mathrm{s}$ damage rate, it would require between 30 and $50 \mathrm{dpa}$ to completely amorphize the $\mathrm{SiC}$. For comparison it would require $<2 \mathrm{dpa}$ at the $\mathrm{Si}$ ion dose rate of $\sim 1 \times 10^{-3} \mathrm{dpa} / \mathrm{s}$. While this model appears to adequately describe the temperature dependence of amorphization at moderate temperatures, it is not entirely satisfying in that it does not exhibit the "critical temperature" asymptotic behavior which is suggested by the data. As the temperature is increased and the exponential term approaches unity, the critical dose for amorphization approaches a constant value of $d_{o}+A / \sqrt{\phi}$. Modification of the Motta and Olander model is necessary to correct this nonphysical predicted amorphization behavior at very high temperatures. The inadequacy of the present model at very high temperatures is seen by noting the unamorphized $\mathrm{Si}$ ion irradiated data point irradiated to $20 \mathrm{dpa}$ at $420 \mathrm{~K}$. The extrapolated Si ion model would fall to the right of this data point (implying the material should have amorphized) and continue to flatten towards a constant value just mentioned.

\section{CONCLUSIONS}

1) There is apparently no PKA spectrum effect in this study on the low temperature (temperature independent) amorphization of $\mathrm{SiC}$ when irradiating with $\mathrm{He}, \mathrm{Si}, \mathrm{Cl}$ and $\mathrm{Fe}$ atoms. However, published low temperature $2 \mathrm{MeV}$ electron and $1.5 \mathrm{MeV}$ Xe irradiations suggest that the low-temperature amorphization dose decreases by about a factor of 5 as the irradiation source is changed from electrons to ions.

2) The critical temperature for amorphization of $\mathrm{SiC}$ with $0.56 \mathrm{MeV} \mathrm{Si}$ of $\sim 420 \mathrm{~K}$ shows an exponential dependence with an apparent critical temperature threshold above which amorphization dose not take place at a damage rate of $\sim 2 \times 10^{-3} \mathrm{dpa} / \mathrm{s}$. This compares with the published amorphization temperature thresholds for $2 \mathrm{MeV}$ electron and $1 \mathrm{MeV}$ Xe ions of $\sim 300$ $\mathrm{K}$ and $500 \mathrm{~K}$ respectively at a similar damage rate.

3) A possible experimental artifact was observed which may affect the calculation of critical dose for amorphization in ion implanted specimens. Specifically, amorphized islands were seen to form with their major radii parallel to the free surface of the specimen. These islands have an aspect ratio of $\sim 3$ which are independent of temperature and crystal orientation. Formation of these islands raises the question of whether surface or strain effects alter the apparent amorphization thresholds in the bulk irradiation method presented here and the thin foil in-situ method which has been used by other workers. A determination of the adequacy of this implantation technique for determining amorphization threshold should be conducted and compared with the in-situ "thin foil" technique.

4) A swelling of approximately $10 \%$ was measured for sintered $\alpha$-SiC and hot pressed $\beta$ $\mathrm{SiC}$ neutron irradiated to $15 \mathrm{dpa}$ at $\sim 350 \mathrm{~K}$. This amount of swelling is about a factor of three higher than previously reported for neutron irradiation at similar temperatures. However, this amount of swelling is less than the $\sim 15$ to $20 \%$ level of swelling observed in completely amorphized ion-irradiated material. It is likely that partial amorphization characterized by amorphous islands is present in the material. XRDA and TEM analysis will be performed to determine the extent of amorphization in the room temperature irradiated samples.

5) A model for the critical dose for amorphization based on the free energy increase associated with point defect accumulation in metals is applied to the temperature dependent critical 
dose for amorphization. An interstitial migration energy of $0.56 \mathrm{eV}$ was calculated based on the Si ion $\left(10^{-3} \mathrm{dpa} / \mathrm{s}\right)$ irradiations and adequately describes the transition from the temperature independent to temperature dependent regimes of amorphization. However, the model does not adequately describe the higher temperature asymptotic amorphization dose behavior. Extrapolation of this model to the dose rate for the neutron irradiated samples $\left(10^{-6} \mathrm{dpa} / \mathrm{s}\right)$ successfully predicts the observed lack of complete amorphization in these specimens. Assuming this dose rate and the interstitial migration energy of $0.56 \mathrm{eV}$, it would require between 30 and 50 dpa to have reached total amorphization for the material neutron irradiated between $-340 \mathrm{~K}$. Presently, a neutron irradiation capsule identical to the one used in this study is in the HFIR reactor and will achieve $60 \mathrm{dpa}$. Examination of the $\mathrm{SiC}$ specimens from this capsule should provide interesting information on the validity of the fitted rate-controlling interstitial migration energy, and whether $\mathrm{SiC}$ can be amorphized during high-dose neutron irradiation at $\sim 340 \mathrm{~K}$.

\section{ACKNOWLEDGMENTS}

The authors would like to thank E. C. Dickey and K. L. More for help with the high resolution microscopy. This work was sponsored by the Office of Fusion Energy Science, U. S. Department of Energy, under contract DE-AC05-96OR22464 managed by Lockheed Martin Energy Research Corp.

\section{REFERENCES}

1. W. Primak, L.H. Fuchs, and P.P. Day, Phys. Rev., 103(5), 1184-1192 (1956).

2. R. Blackstone, J. Nucl. Mater., 39, 319-322 (1971).

3. C.W. White, et al., Nucl. Instrum. Meth. B, 80/81, 41-146 (1989).

4. C.J. McHargue and J.M. Williams, Nucl Instrum Meth,B80/81,889-894 (1993).

5. W.J. Weber, et al., accepted for publication, J. Nucl. Mater., (1996).

6. L.L. Snead, S.J. Zinkle, and D. Steiner, J. Nucl. Mater, 191-194, 560-565 (1992).

7. L.L. Snead and S.J. Zinkle. MRS Symposium \#373 on Microstructure of Irradiated Materials. 1995: Materials Research Society, Pittsburgh Pa. I. M. Robertson, et al. eds.

8. R.R. Hart, H.L. Dunlap, and O.J. March, Rad. Effects, 9, 261-266 (1971).

9. J.M. Williams, C.J. McHargue, and B.R. Appleton, Nucl. Instrum. Meth., 209/210, 317-323 (1983).

10. J. Spitznagel, et al., Nucl. Instrum. Meth., B16, 237-243 (1986).

11. J.A. Edmond, et al., J. Mater. Res., 3, 321-328 (1988).

12. N.G. Chechenin, et al., Nucl. Instrum. Meth., B65, 341-344 (1992).

13. L.L. Horton, et al., Nucl. Instrum. Meth, B65, 345-351 (1992).

14. R.G. Vardiman. Mat. Res. Soc. Symp. 1989.

15. C. Kinoshita, et al. . in Proceedings of the 11th International Conference on Electron Microscopy. 1986: Japanese Society of Electron Microscopy.

16. A. Matsunaga, et al., J. Nucl. Mater., 179-181, 457-460 (1991).

17. H. Inui, H. Mori, and H. Fujita, Phil. Mag., B 61, 107 (1990).

18. H. Inui, H. Mori, and T. Sakata, Phil. Mag. B, 66(6), 737-748 (1992).

19. H. Inui, et al., Phil. Mag., B 65, 1 (1992).

20. S.D. Harrison and J.C. Corelli, J. Nucl. Mater., 99, 203-212 (1981).

21. W.J. Weber and L.M. Wang, Nucl. Instrum. Meth., B 106, 298-302 (1995).

22. W.J. Weber and N. Yu, Accepted Nucl. Instrum. Methods B, (1996).

23. W.J. Weber, L.M. Wang, and N. Yu, Nucl. Instrum. Meth., B 116, 322-326 (1996).

24. W.J. Weber. 13th Internation Cong. on Defects in Insulating Materials. 1996.

25. S.J. Zinkle and L.L. Snead, Nucl. Instrum. Meth. B, 116, 92-101 (1996).

26. J.F. Ziegler, J.P. Biersak, and U.L. Littmark, : Pergamon, New York. 1985 ).

27. A.T. Motta and D.R. Olander, Acta Metta. Mater., 38, 2175-2185 (1990).

28. T.D.de la Rubia, M.-J. Caturla, and M. Tobin. in Microstructure of Irradiated Materials. 1995. Boston, MA. I. M. Robertson, et al. eds. 